\title{
ANÁLISIS DE LA ESTRUCTURA GENÉTICA EN POBLACIONES NATIVAS DEL GRAN CHACO
}

\author{
Analysis of the genetic structure in populations of the Gran Chaco
}

\section{Darío A. Demarchi*}

\section{Resumen}

En este trabajo se presentan algunos análisis sobre la estructura genética de poblaciones nativas del Gran Chaco a partir de la aplicación de dos técnicas analíticas aplicadas a marcadores moleculares de herencia uni y biparental. En general, los resultados muestran que las poblaciones chaqueñas presentan alta diversidad genética y baja diferenciación interpoblacional, en comparación con otras poblaciones sudamericanas, estando presentes un buen número de linajes maternos y paternos, la gran mayoría de ellos compartidos por los distintos grupos de la región. Las distancias genéticas, calculadas a partir de las diferentes variables utilizadas, son bajas y muestran, cada una de ellas, historias diferentes, no coincidiendo con relaciones lingüísticas ni geográficas. Estos resultados podrían estar reflejando patrones culturales anteriores a la colonización europea o bien la ruptura de unidades poblacionales que sobrevino con ésta. Por otra parte, los Ayoreo muestran características genéticas únicas y una diversidad reducida como consecuencia de la acción de algún proceso evolutivo aleatorio, como deriva génica o efecto fundador.

$$
<\text { ADN }><\text { linajes parentales }><\text { distancias genéticas }><\text { flujo génico }><\text { deriva }>
$$

\begin{abstract}
In this article we analyze the genetic structure of native populations of the Gran Chaco, based on two analytical techniques on different molecular markers. Overall, the results show that the Gran Chaco populations have high genetic diversity and low differentiation between populations, when compared to other South American populations, presenting a large number of maternal and paternal lineages, most of them shared by the different groups of the region. Genetic distances, calculated from different molecular markers, are low and show each of them different stories, not coinciding with linguistic or geographical relationships. These results could be reflecting cultural patterns prior to the European colonization or, instead, the rupture of population units that came after it. On the other hand, the Ayoreo show unique genetic characteristics and a reduced genetic diversity as a result of random evolutionary forces, as genetic drift or founder effect.
\end{abstract}

$<$ DNA $><$ parental lineages $><$ genetic distances $><$ gene flow $><$ drift $>$

Recibido: 03/04/2014 // Aceptado: 15/07/2014

\footnotetext{
* Doctor en Ciencias Biológicas, Investigador CONICET, Instituto de Antropología de Córdoba (IDACOR) CONICET/UNC, demarchi@ffyh.unc.edu.ar
} 


\section{Introducción}

El Gran Chaco ocupa el centro de Sudamérica, abarcando parte de los territorios de Argentina, Paraguay y Bolivia. Es una llanura de aproximadamente un millón de kilómetros cuadrados, situada en el ámbito de las Tierras Bajas Sudamericanas. Los ríos Pilcomayo, Bermejo y sus afluentes tienen una dinámica estacional que determina paisajes aluvionales. Han experimentado desbordes y también notables retrocesos en su cauce. Esto, sumado a diferencias muy marcadas entre la estación seca y la húmeda condicionó el establecimiento de grupos humanos en la zona, siendo considerada como una de las regiones más tardíamente ocupadas del continente (Calandra y Salceda, 2004; Ramallo et al., 2009).

Tradicionalmente, los aborígenes chaqueños vivían organizados en tribus, integradas por bandas constituidas por familias extensas, y seguían una vida nómada de cazadores-pescadores-recolectores (Tomasini y Braunstein, 2006). La colonización europea llevó a una reorganización demográfica, con importantes movimientos migratorios. Las campañas militares, las misiones evangelizadoras, la apertura de rutas y vías férreas, además de la integración al Estado Nacional, fueron procesos que aún continúan ocasionando cambios y generando estrategias de reproducción cultural en el nuevo rol de actores sociales en vecindad a los centros urbanos (Braunstein, 1983).

En este artículo se investigan los patrones de diversidad y relaciones genéticas entre poblaciones aborígenes del Gran Chaco y de regiones geográficas vecinas a partir del análisis de marcadores moleculares de herencia uniparental (ADN mitocondrial y cromosoma Y) y biparental (microsatélites autosómicos), con el objetivo de identificar las fuerzas evolutivas que modelaron la variación genética actual.

\section{Materiales y métodos}

Para facilitar la comprensión por parte de lectores de otras disciplinas, comenzaremos definiendo algunos conceptos teóricos y metodológicos utilizados en este estudio. Básicamente, la genética de poblaciones estudia la evolución de las poblaciones a partir de modelos matemáticos. Por estructura de la población los genetistas de poblaciones se refieren a que, en lugar de una sola población única y homogénea, las poblaciones generalmente se subdividen en alguna forma. A la población total (que en este caso correspondería a la población humana del Gran Chaco) a menudo se la designa como metapoblación, mientras que a las poblaciones individuales se las llama subpoblaciones, o bien poblaciones locales o demes. De hecho, en muchas poblaciones reales puede que no exista estructura y la variación genética sea continua a través de todo el espacio geográfico. Sin embargo, incluso en poblaciones efectivamente continuas, las diferentes áreas pueden presentar diferentes frecuencias genéticas, debido a que la metapoblación no es panmíctica (panmixia: sistema de apareamiento en el que la elección de pareja se realiza al azar). Una definición de estructura de la población, entonces, es cualquier desviación que las poblaciones tienen de la panmixia. Si existe endogamia dentro de las subpoblaciones, o presiones diferentes debido a un ambiente no homogéneo, o si la migración desde el exterior de la región es importante sólo hacia 
alguna de las subpoblaciones mientras que otras permanecen aisladas, puede decirse que las poblaciones presentan estructura (Jobling et al., 2004, Relethford, 2012).

En ambientes más o menos homogéneos, como los que presenta el Gran Chaco Sudamericano, la selección natural (entendida como reproducción diferencial de algunos genotipos/fenotipos) puede ser descartada como agente de cambio genético en la mayoría de los casos. No porque no actúe, sino porque lo hace de manera más o menos homogénea a través de todo el espacio geográfico. Así, las variaciones entre subpoblaciones son atribuibles mayormente a otras dos fuerzas evolutivas: el flujo génico, que introduce nuevos alelos en el seno de la población (y cuyo principal impacto evolutivo es reducir las diferencias genéticas entre poblaciones), y la deriva génica, que puede ser entendida como la fluctuación aleatoria en las frecuencias alélicas en el tiempo (y cuyo mayor impacto es incrementar la diferenciación genética entre poblaciones). La acción de la deriva génica es particularmente intensa en poblaciones pequeñas y aisladas (Jobling et al., 2004, Relethford, 2012).

Un buen estimador de la estructura genética de una población es el estadístico $F_{S T}$ (Wright, 1951), conocido como coeficiente de diferenciación interpoblacional. El $\mathrm{F}_{\mathrm{ST}}$ mide la distribución de la variación genética entre subpoblaciones, es decir, compara la diversidad genética media de las subpoblaciones con la diversidad genética de la metapoblación. El $\mathrm{F}_{\mathrm{ST}}$ puede estimarse como: $F_{S T}=\left(H_{T}-H_{S}\right) / H_{T}$ donde $H_{T}$ es la heterocigosis esperada de la metapoblación y $H_{S}$ es la heterocigosis media esperada en las subpoblaciones. El $\mathrm{F}_{\mathrm{ST}}$ puede variar entre $0 \mathrm{y} 1$. Cuando el flujo génico es alto y hay poca diferenciación entre subpoblaciones, el $\mathrm{F}_{\mathrm{ST}}$ es bajo, cercano a cero. Cuando las subpoblaciones están muy diferenciadas entre sí (actúa la deriva génica), la diversidad genética de la metapoblación $\left(\mathrm{H}_{\mathrm{T}}\right)$ es mucho mayor que la de las subpoblaciones $\left(\mathrm{H}_{\mathrm{S}}\right)$ y el $\mathrm{F}_{\mathrm{ST}}$ es cercano a 1 . En poblaciones humanas, el $\mathrm{F}_{\mathrm{ST}}$ varía entre valores cercanos a 0 hasta estimaciones entre 0,05 y 0,15 .

Distancias genéticas. Constituyen una medida relativa de la divergencia genética entre especies o entre poblaciones de una misma especie. Se mide por una variedad de parámetros, elaborados de acuerdo al grado de divergencia y a la naturaleza de las variables utilizadas para su cálculo. Distancias genéticas pequeñas indican una estrecha relación genética mientras que distancias genéticas grandes indican una relación genética más distante. Las diferencias en las frecuencias génicas se transforman en distancias entre poblaciones. Éstas son usadas para inferir relaciones evolutivas entre ellas. La distancia genética entre dos poblaciones será pequeña si: 1) comparten un ancestro común reciente; 2) intercambian genes (flujo génico); 3) tienen igual presión selectiva; 4) las poblaciones son grandes. En consecuencia, es necesario conocer a priori, aunque sea parcialmente, algunos parámetros poblacionales para poder realizar inferencias correctas a partir del análisis de distancias genéticas (Demarchi, 2009).

Modelo de Harpending y Ward (1982). Este análisis se utiliza para estimar los roles relativos que han tenido, a través del tiempo en la diferenciación biológica entre 
las poblaciones, las fuerzas sistemáticas -selección natural y flujo génico-, predecibles en cuanto a la intensidad y dirección, y las fuerzas dispersivas -mutación y deriva génica-, aleatorias en cuanto a la dirección pero con un cierto grado de previsibilidad en cuanto a la intensidad. Se calcula mediante la regresión lineal de los valores de diversidad genética sobre las desviaciones de las frecuencias alélicas de cada población en relación a la frecuencia promedio de la población total. De acuerdo a este modelo, bajo presión sistemática uniforme (flujo génico), existe una correlación lineal y negativa entre la diversidad genética observada y la distancia genética de cada población al centroide $\left(\boldsymbol{r}_{i i}\right)$, éste correspondería al antecesor común, antes de la subdivisión. Las poblaciones que recibieron desde el exterior flujo génico mayor al promedio tendrán una diversidad mayor a la predicha por regresión. De manera contraria, las poblaciones que experimentaron aislamiento (dando lugar a la acción de deriva génica) mostrarán valores por debajo de la línea de regresión. Una descripción más detallada sobre su cálculo y la aplicación a diferentes tipos de datos puede encontrarse en Reddy et al. (2001).

\section{Poblaciones y marcadores utilizados}

\section{Microsatélites autosómicos (STRs)}

Se incluyeron en este análisis 17 poblaciones nativas del Cono Sur, entre las que se cuentan 6 del Gran Chaco: Pilagás del departamento Patiño (Formosa), Tobas de Castelli (Chaco), Tobas de la comunidad NanQom (Formosa capital), Wichís del norte de Formosa (El Potrillo, La Brea, Pozo Yacaré), Wichís de la provincia del Chaco (El Sauzalito) y Ayoreos del norte de Paraguay. Las otras poblaciones analizadas fueron una muestra de la Puna salteña y Mapuches de Chubut y de Río Negro, Caingang, Xavante, Guaraní, Gaviao, Suruí, Zoró y Wai-Wai, de Brasil y Aché del Paraguay. Se estudiaron 15 STRs (todos ellos tetraméricos), correspondiente a los loci D2S1338, D3S1358, D5S818, D7S820, D8S1179, D13S317, D16S539, D18S51, D19S433, D21S11, FGA, vWA, CSF1PO, TPOX, y TH01. Información adicional sobre los sistemas estudiados y procedencia de las muestras son detallados en el trabajo de Demarchi(2009). Brevemente, los microsatélites o STRs (short tandem repeats en inglés) son secuencias cortas de $\mathrm{ADN}$, generalmente de 1 a 4 pares de nucleótidos, que se repiten en bloque a lo largo de la molécula de ADN. En antropología biológica, estos polimorfismos se han convertido en los marcadores de elección en un número creciente de estudios, debido a algunas ventajas que presentan por sobre otros marcadores genéticos: (1) son encontrados en gran número y esparcidos uniformemente a través del genoma; (2) dada su alta tasa de mutación (entre $10^{-3}$ y $10^{-4}$ ), la mayoría son polimórficos, aun en poblaciones donde existe baja variabilidad en otros marcadores (proteínas, ADN mitocondrial); (3) la mayoría son selectivamente neutros, con lo cual resultan compatibles con los postulados de la genética de poblaciones; (4) son relativamente fáciles de tipificar y los distintos alelos pueden ser caracterizados sin ambigüedades; (5) el análisis por PCR de pequeños fragmentos de ADN permite la tipificación de muestras muy degradadas. 
Para el análisis de distancias se utilizó la distancia $D_{A}$ (Nei et al., 1983), utilizada frecuentemente con microsatélites debido a que se ha demostrado que es la que mejor representa las relaciones poblacionales, tanto a partir de datos teóricos (Takezaki y Nei, 1996) como empíricos (Takezaki y Nei, 2008).

\section{Marcadores de herencia uniparental}

Existen dos fracciones del genoma que han recibido especial atención en estudios bioantropológicos debido a la gran cantidad de información que brindan sobre la evolución de la población: el ADN mitocondrial y la región Y-específica del Cromosoma Y. Ambas son regiones de ligamiento completo, que se transmiten en bloque de una generación a la siguiente, es decir que carecen de recombinación, y por lo tanto las mutaciones se acumulan en forma secuencial. El ADN mitocondrial y la región Y-específica del Cromosoma Y presentan una serie de marcadores que ayudan a identificar linajes genéticos específicos (maternos y paternos respectivamente), presentes en grupos humanos. A través del análisis de la variación de la secuencia en esos dos genomas se pueden identificar los linajes genéticos presentes dentro de las poblaciones e inferir la manera en que esos linajes se dispersaron a lo largo de determinadas áreas geográficas. Se han identificado mutaciones en el ADNmt que definen cuatro linajes maternos (A, B, C y D) (Schurr et al. 1990, Torroni et al. 1993) presentes en más del $90 \%$ de los nativos americanos actuales. Existe un quinto linaje (X), pero es mucho menos frecuente y se ha observado solamente en poblaciones de América del Norte. Por su parte, también existen variantes genéticas en la región no recombinante del cromosoma Y que permiten identificar el origen geográfico y étnico de linajes paternos, entre ellas la mutación M3, que define al haplogrupo Q1a3a que está presente en más del 90\% de los varones americanos (Underhill 1996, Santos et al. 1999).

\section{Haplogrupos del ADN mitocondrial}

El análisis se llevó a cabo sobre 28 poblaciones, incluyendo las poblaciones mencionadas más arriba y otras provenientes de diferentes regiones de Sudamérica, utilizando datos propios y otros publicados en la literatura especializada. Referencias sobre la procedencia de las muestras fueron publicadas en el artículo de García y Demarchi (2009). Para el análisis de distancias se utilizaron las distancias $D^{2}$, obtenidas por el método de la matriz R (Harpending y Jenkins, 1973).

\section{Microsatélites del cromosoma Y (linajes americanos)}

Se incluyeron en este análisis 17 muestras poblacionales sudamericanas, utilizando datos propios (Demarchi y Mitchell, 2004; Altuna et al., 2006) e información publicada por otros autores. Para el análisis de distancias se utilizaron las distancias $R_{S T}$, implementadas en el programa Arlequin, versión 3.11 (http://cmpg.unibe.ch/ software/arlequin3), las que fueron calculadas a partir de la distribución de haplotipos determinados por 5 microsatélites (DYS19, DYS390, DYS391, DYS392, DYS393), 
incluyendo solamente aquellos individuos que pertenecientes al haplogrupo Q1a3a, de origen americano.

Una vez obtenidas las matrices de distancias se construyeron mapas genéticos mediante escalamiento multidimensional (non-metric multidimensional scaling, NMS, Kruskal, 1964).

\section{Resultados}

\section{Análisis de microsatélites autosómicos}

La Figura 1 es la proyección bidimensional de la matriz de distancias $D_{A}$. Las poblaciones del Chaco argentino ocupan el centro del gráfico, a bajos valores de distancia entre ellas, particularmente Wichí y Toba de Formosa y Toba de Chaco. Los Pilagá aparecen un poco más alejados, cercanos a los puneños y a los mapuches de Chubut. En posición marginal, a grandes valores de distancia entre sí y con respecto a las demás aparecen las muestras Aché, Ayoreo, Suruí y Wichí del Chaco, constituyendo de esta manera outliers dentro del conjunto.

Figura 1*. Escalamiento bidimensional de la matriz de distancias DA basado en microsatélites autosómicos

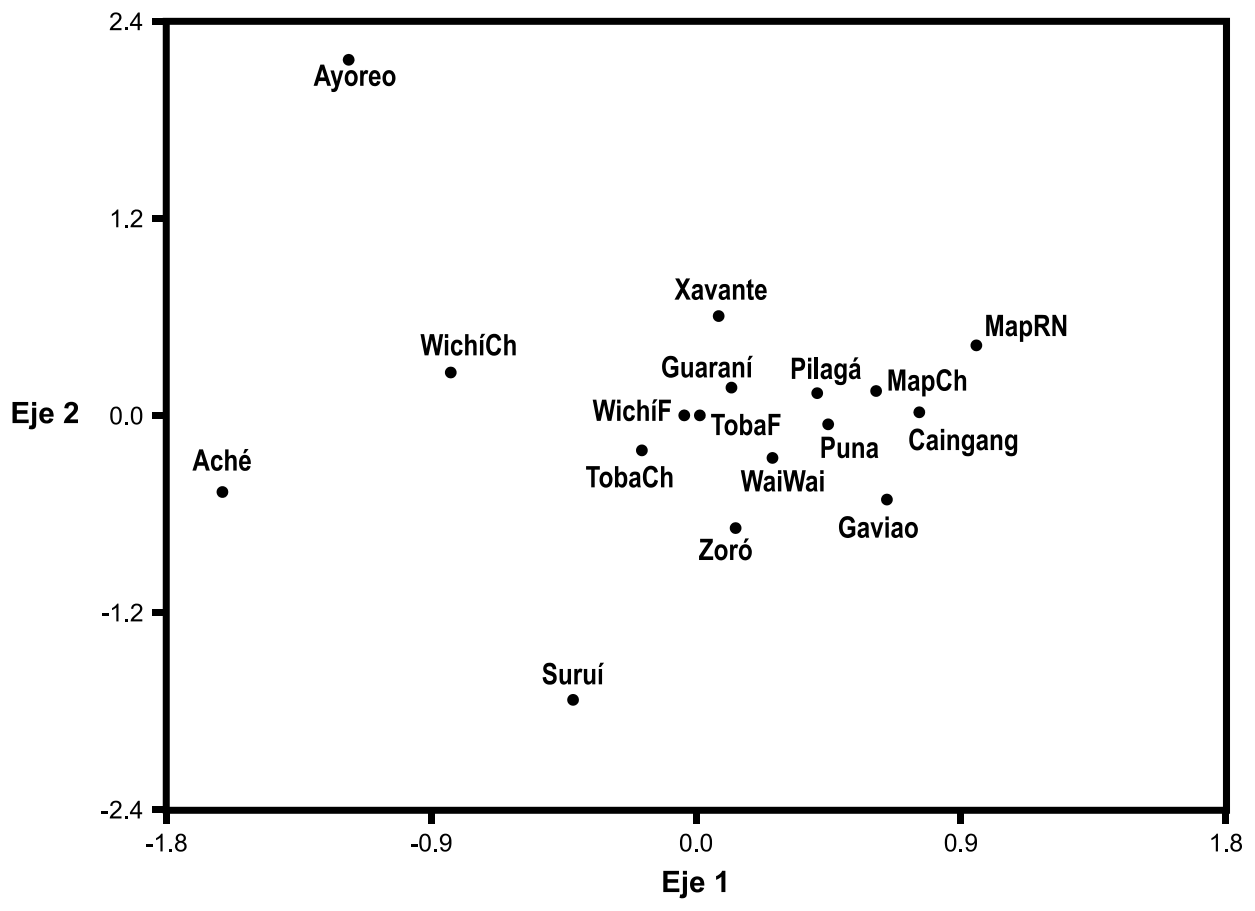

\footnotetext{
* Abreviaturas: MapRN, Mapuche Río Negro; MapCh, Mapuche Chubut; TobaCh, Toba Chaco; TobaF, Toba Formosa; WichíCh, Wichí Chaco; WichíF, Wichí Formosa.
} 


\section{Análisis de Harpending y Ward}

En la Figura 2 se observa que las muestras poblacionales Wichí y Toba de Formosa se ubican cercanas al origen, levemente por debajo de la línea de regresión y próximos entre sí. Esta posición sugiere un tamaño efectivo relativamente grande, por lo cual se han diferenciado poco de la población ancestral y, por otra parte, sugiere la existencia de flujo génico entre ambas poblaciones. Las muestras Wai-wai, Guaraní, Toba del Chaco y Xavante se ubican próximos a la línea de regresión, de acuerdo a lo que predice el modelo (en equilibrio entre la diversidad genética observada y la distancia al origen). La ubicación por encima de la recta de Pilagá, al igual que las muestras Puna, ambas Mapuches y Caingang, sugiere que estas poblaciones han recibido flujo génico diferencial desde el exterior (es decir, de poblaciones no incluidas en el análisis), presumiblemente por mestizaje con población no americana. Reforzando esta suposición, se ha observado en los Pilagá una mayoría de linajes paternos no nativos (Demarchi y Mitchell, 2004) y algunos linajes maternos africanos (datos no publicados). Por otra parte, es conocida la existencia de un componente no amerindio en el pool génico de las poblaciones mapuches (Carnese et al., 1996) y de la Puna, si bien no se conoce exactamente el grado de mestizaje en esta última región (Albeza et al., 2002). Lo mismo puede decirse de los Caingang, quienes han sufrido en las últimas décadas un alto grado de aculturación (Kohlrausch et al., 2005). El resultado más notorio de este análisis es la posición que ocupan en el gráfico Ayoreo, Suruí y Aché, muy distantes del origen y con una diversidad genética extremadamente reducida. Esta situación sugiere aislamiento reproductivo y tamaños efectivos pequeños. Si bien los Ayoreo y los Aché no presentan tamaños poblacionales tan bajos, lo cual si se verifica entre los Suruí, sus tamaños efectivos se encuentran muy reducidos ${ }^{1}$, tal cual lo evidencia el bajo número de linajes maternos existente en esas poblaciones (Dornelles et al., 2004; Schmitt et al., 2004). La pérdida de diversidad genética estaría reflejando la acción de fuerzas aleatorias tales como deriva genética, cuello de botella o efecto fundador. Los Wichí del Chaco también se ubican por debajo de la línea de regresión y bastante lejos de los demás grupos del Chaco argentino, lo cual concuerda con lo encontrado en otros trabajos donde ya se había observado la pérdida de diversidad en esta población (Demarchi et al., 2001; Demarchi y Mitchell, 2004). El coeficiente de diferenciación interpoblacional es relativamente alto $\left(F_{S T}=0,055\right)$, pero son estas últimas 4 poblaciones las que más contribuyen a ese valor de diferenciación interpoblacional.

1 Es decir, hay muchos individuos pero éstos descienden de unos pocos ancestros, por lo cual comparten el mismo genoma. Así, a pesar de que la población pueda tener un tamaño censal grande, su tamaño efectivo es extremadamente pequeño. Este fenómeno, común en poblaciones humanas, se produce principalmente a partir de dos procesos: efecto fundador y cuello de botella genético (ver Jobling et al., 2004, Cap. 5). 


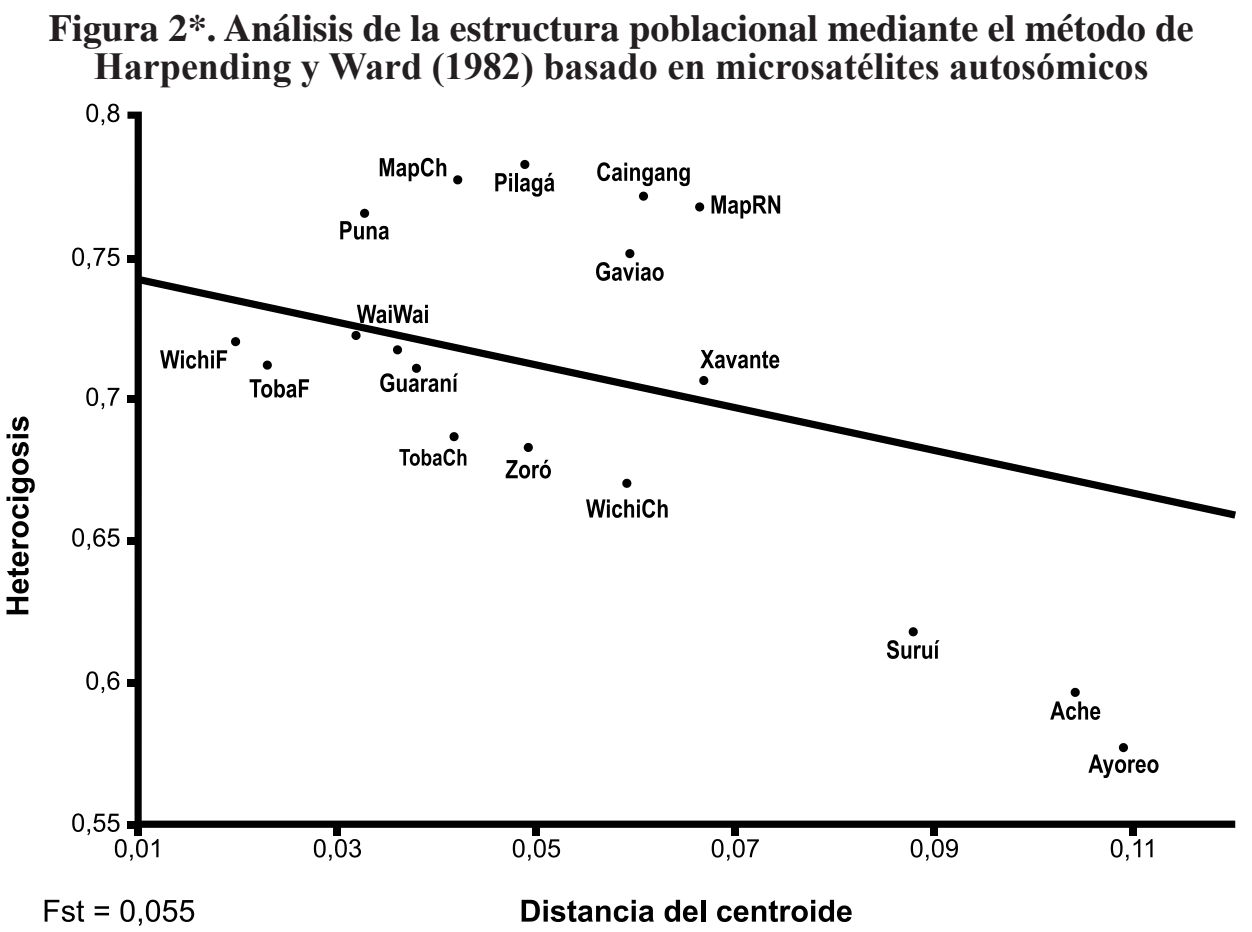

\section{ADN mitocondrial}

\section{Distancias genéticas}

En la Figura 3 se representa las similitudes relativas entre poblaciones sudamericanas basadas en frecuencias relativas de haplogrupos mitocondriales americanos. En general, la distribución de las muestras se ajusta de manera bastante precisa a la distribución geográfica de las mismas. Las poblaciones de Patagonia se agrupan a bajos valores de distancia entre sí, al igual que lo hacen las de los Andes centrales y las de las tierras bajas de Bolivia (Trinitare, Ignaciano y Yuruí). Las poblaciones del Chaco argentino también se ubican muy cerca unas de otras, en el centro del gráfico. Por otra parte, los Ayoreo del Chaco Boreal se ubican muy lejos de éstas, en una posición marginal, en el extremo superior derecho de la figura. Las otras poblaciones que aparecen en posición marginal son Alakaluf, Aché y Mbyá, todas caracterizadas por una pérdida muy marcada de la diversidad debido a procesos aleatorios (Fox 1996, Dornelles et al., 2004, Altuna et al., 2006). Las poblaciones que ocupan el centro del gráfico, por el contrario, se caracterizan por una alta diversidad genética, característica que refleja un mayor tamaño efectivo y la existencia de flujo génico sostenido. Así,

\footnotetext{
* Abreviaturas: MapRN, Mapuche Río Negro; MapCh, Mapuche Chubut; TobaCh, Toba Chaco; TobaF, Toba Formosa; WichíCh, Wichí Chaco; WichíF, Wichí Formosa.
} 
además de mostrar similitudes debidas a la distribución geográfica de las poblaciones, el gráfico revela también la historia demográfica reciente de las poblaciones.

\section{Figura 3*. Escalamiento bidimensional de la matriz de distancias D2 basado en haplogrupos mitocondriales}

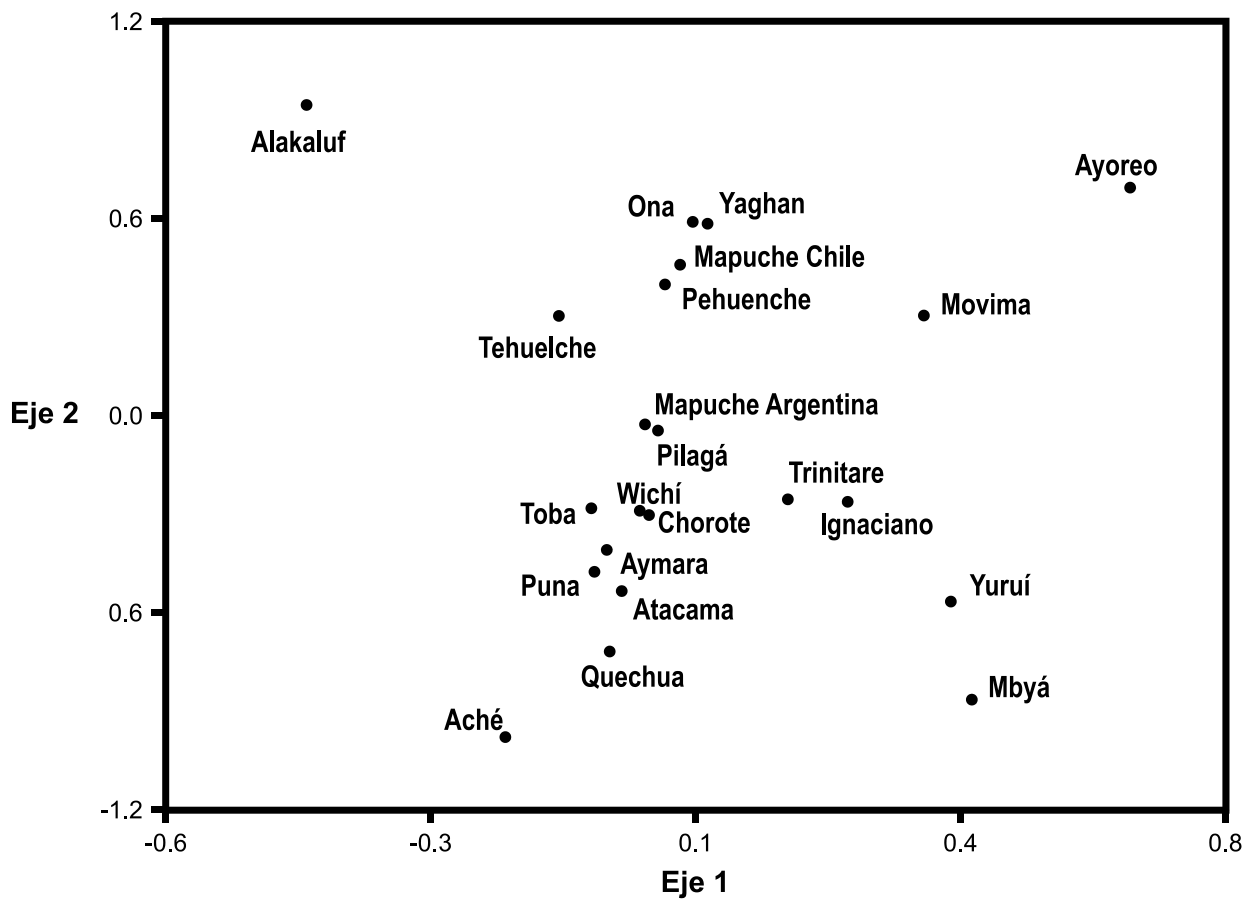

\section{Análisis de Harpending y Ward}

Al igual que en el análisis a partir de microsatélites autosómicos, las poblaciones del Chaco Argentino se ubican cercanas al origen (a la población ancestral teórica), y a la recta de regresión, lo cual sugiere un tamaño efectivo grande, también en cuanto al genoma mitocondrial. Los Ayoreo se ubican de nuevo muy lejos del origen y por debajo de la línea de regresión, situación que confirma la pérdida de diversidad genética y la acción de la deriva en esa población. El $F_{S T}$ es sumamente alto $(0,234)$, más de 4 veces el observado a partir de microsatélites autosómicos, lo cual es esperable dado que el tamaño efectivo del genoma mitocondrial es 4 veces menor debido a que es un genoma haploide y se hereda sólo por vía materna. De esta forma, es mucho más sensible a procesos evolutivos aleatorios, como la deriva o el efecto fundador (Jobling et al., 2004).

\footnotetext{
* Abreviaturas: MapChile, Mapuches Chile; MapArg, Mapuches Argentina.
} 
Figura 4*. Análisis de la estructura poblacional mediante el método de Harpending y Ward (1982) basado en haplogrupos mitocondriales

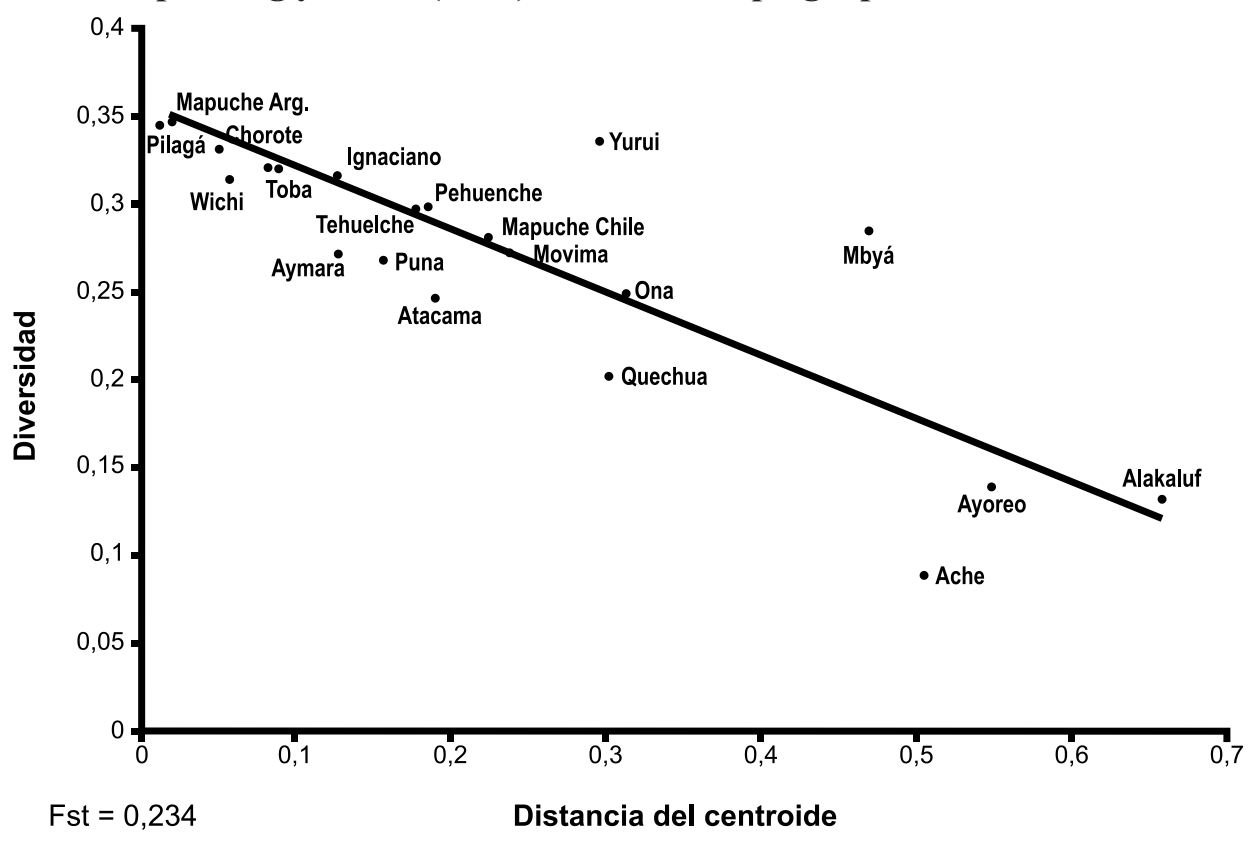

\section{Cromosoma Y}

\section{Distancias genéticas}

La Figura 5 representa las distancias $\mathrm{R}_{\mathrm{ST}}$ entre 17 muestras poblacionales calculadas a partir de haplotipos del cromosoma $\mathrm{Y}$ basados en 5 microsatélites. Las relaciones intermuestrales difieren de las observadas en los anteriores análisis. Las poblaciones chaqueñas continúan ocupando el centro del gráfico, a bajos valores de distancia entre sí. La novedad es que los Ayoreo se ubican aquí muy cerca de las muestras del Chaco argentino y no en la posición marginal que ocupaban en los análisis anteriores. Como outliers al arreglo aparecen Ticuna, Wayuu, y Humahuaca. A pesar del pequeño tamaño de la muestra Ayoreo (6 individuos) es posible inferir que el genoma haploide del cromosoma $\mathrm{Y}$ no presenta una diversidad reducida, si bien esta afirmación debe ser tomada con precaución ya es inferida a partir de sólo 5 marcadores.

\footnotetext{
* Abreviaturas: MapChile, Mapuches Chile; MapArg, Mapuches Argentina.
} 
Figura 5*. Escalamiento bidimensional de la matriz de distancias RST basado en microsatélites del cromosoma $Y$

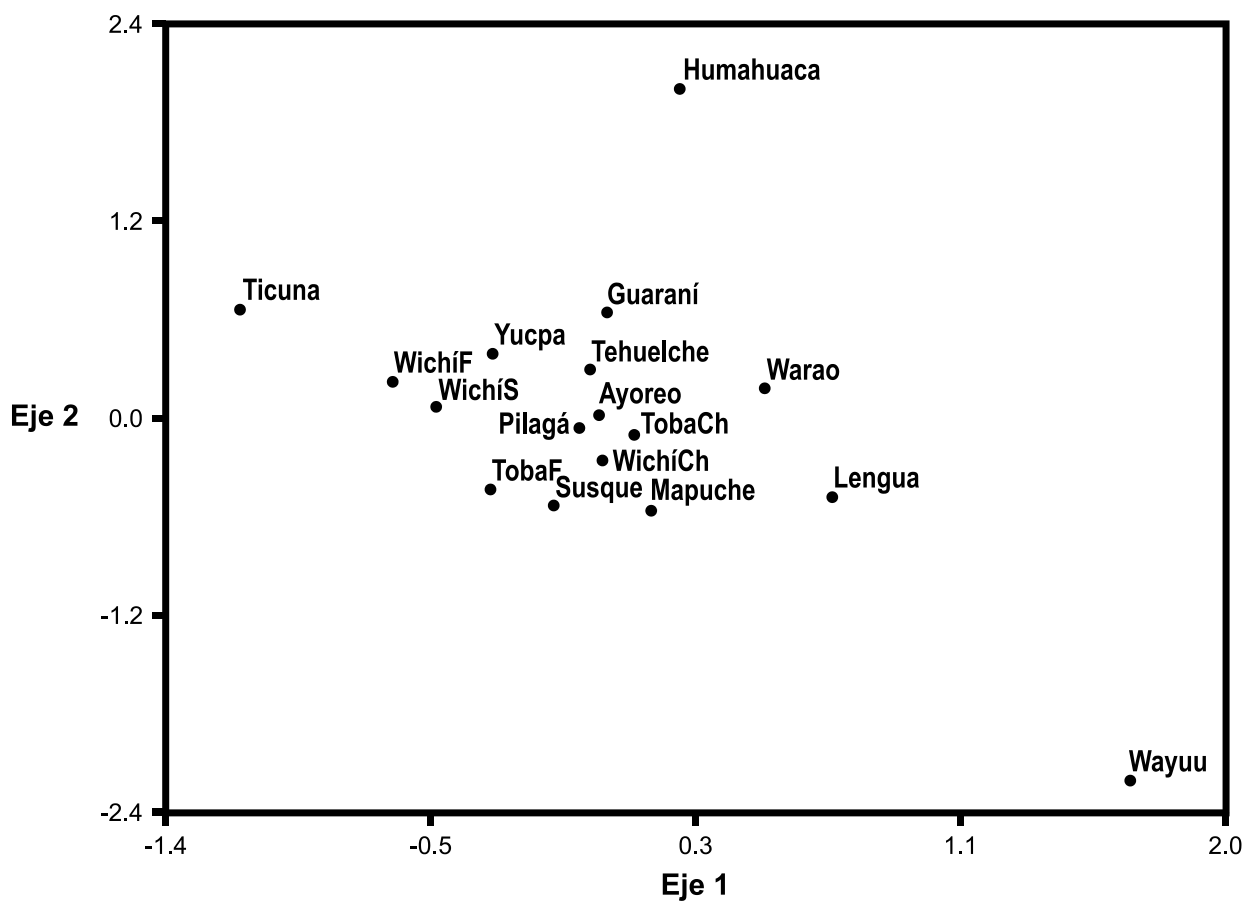

\section{Análisis de Harpending y Ward}

Los grupos chaqueños aparecen cercanos al origen, como en los anteriores análisis, lo cual puede interpretarse como poca diferenciación a partir de la poblacion ancestral. Sin embargo muestran diversidad genética por debajo del promedio, salvo en el caso de los Wichí de Chaco. Humahuaca aparece como el grupo más diferenciado del resto, a grandes valores de distancia desde el origen. Su posición, bien por encima de la recta de regresión, sugiere que la diferenciación no obedece a un proceso aleatorio y a pérdida de diversidad sino a flujo génico desde afuera de la región, muy probablemente por aporte de migrantes no americanos. $E l F_{S T}$ es levemente inferior al observado a partir de haplogrupos mitocondriales $(0,196)$, pero del mismo orden, resultado que es coherente debido a que el tamaño efectivo del genoma del cromosoma Y es también equivalente a $1 \frac{4}{4}$ del genoma autosómico, y refleja de tal forma una acción proporcional de las fuerzas evolutivas aleatorias sobre la población.

\footnotetext{
* Abreviaturas: TobaCh, Toba Chaco; TobaF, Toba Formosa; WichíCh, Wichí Chaco; WichíS, Wichí Salta.
} 


\section{Figura 6*. Análisis de la estructura poblacional mediante el método de Harpending y Ward (1982) basado en microsatélites del cromosoma $Y$}

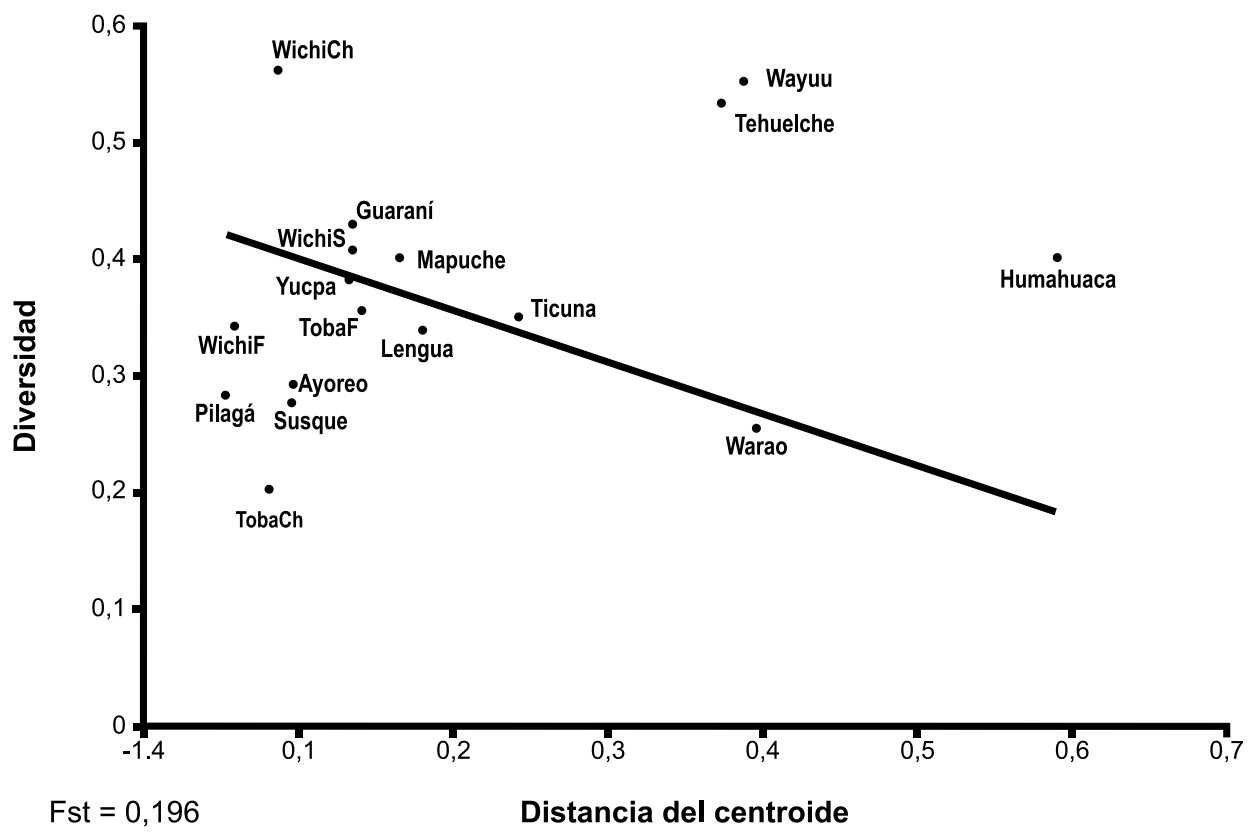

\section{Discusión}

El objetivo principal del trabajo fue evaluar los patrones de variación genética a nivel regional (Gran Chaco) y continental, para poder realizar inferencias acerca de las fuerzas evolutivas que modelaron dicha variación. Teniendo en cuenta esta premisa, es necesario dejar en claro que los distintos análisis (a partir de STRs autosomales, de frecuencias de haplogrupos mitocondriales y de haplotipos del cromosoma Y) no incluyeron exactamente las mismas muestras poblacionales y que éstas no representan todas las disponibles actualmente en la literatura especializada para América del Sur. Teniendo en cuenta el objetivo del trabajo, el carácter heterogéneo de la muestra y la relativa representatividad de las mismas no invalidan los resultados obtenidos.

En el Chaco argentino existe una gran diversidad de linajes maternos (Cabana et al., 2006) y paternos (Demarchi y Mitchell, 2004), la mayoría compartidos por los distintos grupos de la región y, algunos, por poblaciones de regiones vecinas (Pauro et al., 2013). Por otra parte, los coeficientes de diferenciación interpoblacional son relativamente bajos en comparación con los observados en otras regiones sudamericanas (Demarchi et al., 2001, Demarchi y Mitchell, 2004). En consecuencia, las distancias genéticas, calculadas tanto a partir de marcadores autosómicos como de linajes uniparentales maternos y paternos, son bajas y muestran relaciones biológicas diferentes,

\footnotetext{
* Abreviaturas: TobaCh, Toba Chaco; TobaF, Toba Formosa; WichíCh, Wichí Chaco; WichíS, Wichí Salta.
} 
no coincidiendo con relaciones lingüísticas ni geográficas (Demarchi y Mitchell, 2004). Estos resultados podrían estar reflejando patrones culturales anteriores a la colonización europea o bien la ruptura de unidades poblacionales que sobrevino con ésta.

$\mathrm{Su}$ localización intermedia respecto a otras regiones geográfico-ecológicas (Andes, Pampa, selvas tropicales) puede haber contribuido a aumentar la diversidad genética humana a través del flujo génico desde y hacia la región (Demarchi et al., 2001). Una predicción hecha a partir de esta posible explicación sería que la distancia promedio de las poblaciones chaqueñas con las demás poblaciones de América del Sur sería menor que la de las poblaciones de cualquier otra región (Cabana et al., 2006). Excluyendo los Ayoreo, esto es claramente lo que se observa en nuestros resultados, como se confirma visualmente en las representaciones gráficas de las distancias genéticas realizadas a partir de los diferentes marcadores, donde las poblaciones chaqueñas ocupan siempre el centro del gráfico y se ubican relativamente cercanas entre sí y relativamente más cercanas a las demás poblaciones.

La consistencia del patrón de diversidad entre las etnias chaqueñas, es decir alta diversidad genética intrapoblacional y baja diferenciación interpoblacional, sugiere una historia poblacional común y constituye un rasgo distintivo de la región (Demarchi et al., 2001; Demarchi y Mitchell, 2004; Cabana et al., 2006; Crosetti et al., 2008). Esa historia parece haber sido modelada por factores ecológicos, demográficos e históricos. Bandas de cazadores recolectores en un ambiente semiárido relacionadas entre sí por redes de intercambio y matrimonio. Estas redes fueron fundamentales para establecer alianzas que permitían el acceso a los recursos (áreas de caza y pesca), por lo que la singular homogeneidad de linajes maternos no es sorprendente (Cabana et al., 2006).

Según Braunstein (1983), las etnias chaqueñas se organizaban en unidades políticas, las tribus, integradas por un número variable de bandas, las que estaban constituidas por familias extensas. Sus integrantes mantenían entre sí lazos de parentesco por descendencia o matrimonio. Estos modelos de organización van a modificarse a medida que la región es colonizada y ya no puede mantenerse una individualización a partir de la explotación de territorios específicos. El proceso de sedentarización implicó una serie de ajustes a nivel sociopolítico y una reorganización demográfica, con importantes movimientos migratorios. Las campañas militares, el establecimiento de misiones evangelizadoras, el desarrollo de las industrias azucareras y madereras y la apertura de rutas y vías férreas en la región chaqueña durante los siglos XIX y XX, además de la integración al Estado Nacional, fueron procesos que aún continúan ocasionando cambios y generando estrategias de reproducción cultural en el nuevo rol de actores sociales en vecindad a los centros urbanos (Braunstein, 1983).

Los resultados sugieren la proximidad genética entre las familias lingüísticas Mataco y Guaykurú, lo que implica un flujo de genes sostenido entre ellas. Por lo cual podemos afirmar que el lenguaje no parece ser una barrera importante para el flujo de genes en esta región. Las antiguas formas de vida de esos pueblos, relacionadas con las condiciones ecológicas de la región, dieron lugar a migraciones estacionales. En una región donde la comida es escasa, la probabilidad de contacto entre pequeños 
grupos nómadas de diferentes orígenes sería alto, especialmente en los lugares donde se encontraron agua y otros suministros con más facilidad (Tomasini y Braunstein, 2006).

Los Ayoreo constituyen una excepción a este patrón de variación, modelado principalmente por el flujo génico. Los datos obtenidos a partir de grupos sanguíneos, proteínas séricas y rasgos morfológicos craneales muestran una variación genética reducida en este grupo y una diferenciación muy significativa con respecto a las otras poblaciones de la región (Salzano et al., 1978; Demarchi et al., 1998). Diferencias similares aunque no tan evidentes se observaron a partir de inserciones Alu investigadas por Dornelles et al., (2004), quienes interpretan que este patrón de diversidad reducida es consecuencia de efecto fundador. El relativo aislamiento reproductivo de esta población en relación a los grupos nativos vecinos, contribuye a que este fenómeno no haya sido revertido y continúe siendo parte de la característica distintiva de la población. Por otra parte, los resultados obtenidos a partir de proporciones craneanas, determinadas por herencia poligénica y, por lo tanto, evolutivamente más estable, sugieren que esta población podría tener un origen diferente al de los grupos "típicos" del Gran Chaco (Demarchi et al., 1998).

Los patrones de la estructura genética en el Chaco Central en tiempos prehispánicos han sido severamente afectados tras la irrupción de los europeos a la región modificando los sistemas de apareamiento y de explotación del ambiente (Mendoza, 2003). El análisis de ADN antiguo de restos mortuorios de los pueblos que habitaban la zona antes de la llegada de los europeos será de gran ayuda para evaluar hasta qué grado los procesos postcontacto afectaron la estructura genética de la población del Gran Chaco.

A pesar de las limitaciones derivadas de la relativa representatividad de las muestras y de las modificaciones en el modo tradicional de vida de sus habitantes, particularmente severas durante el último siglo, podemos concluir que en el Gran Chaco el flujo génico es la fuerza evolutiva que más ha contribuido a modelar la alta diversidad genética de sus poblaciones, tanto a lo largo de su historia prehispánica como a partir del contacto con los migrantes europeos.

\section{Agradecimientos}

Agradezco a Susana Salceda, Horacio Calandra y Guillermo Lamenza la invitación al Simposio "Arqueología del Gran Chaco y su periferia: actualización en su conocimiento", en el marco del "XVIII Congreso Nacional de Arqueología Argentina", y también por permitirme participar con los resultados allí expuestos en esta publicación.

\section{Bibliografía}

Albeza, M. V.; Picornell A.; Acreche, N.; Tomas, C.; Castro, J. A. y Ramon, M. M. 2002. "Genetic variability at 14 STR loci in the Puna population of north western Argentina". International Journal of Legal Medicine. 116, pp. 126-132. 
Altuna, M. E.; Modesti, N. y Demarchi, D. A. 2006. "Y Chromosomal evidence of founder effect in Mbya-Guaraní Amerindians of Northeast Argentina”. Human Biology 78, pp. 635-639.

Braunstein, J. 1983. “Algunos rasgos de la organización social de los indígenas del Gran Chaco”. Trabajos de Etnología. Instituto de Ciencias Antropológicas, Facultad de Filosofía y Letras, Universidad Nacional de Buenos Aires. Publicación No 2 . Buenos Aires, Argentina.

Cabana, G.; Merriwether, A. D.; Hunley, K. L. y Demarchi, D. A. 2006. "Is the genetic structure of Gran Chaco populations unique? Interregional perspectives on Native South American mitochondrial DNA variation." American Journal of Physical Anthropology 131, pp. 108-119.

Calandra, H. y Salceda, S. 2004. "El territorio y sus ocupantes: ¿qué, quiénes, cómo y cuándo?" En: Folia Histórica del Nordeste. Vol. 15, pp. 107-128.

Carnese, F. R.; Caratini, A.; Goicoechea, A.; Weimer T. A.; Franco, M.; Hutz, M. H. y Salzano, F. M. 1996. "Demography and blood genetics of Argentinian Mapuche Indians.” International Journal of Anthropology 11 (2-4), pp. 33-42.

Crossetti, S. G.; Demarchi, D. A.; Raimann, P. E.; Salzano, F. M.; Hutz, M. H. y Callegari-Jacques, S. M. (2008) Autosomal STR genetic variability in the Chaco native population: homogeneity or heterogeneity? Am. J. Human Biology 20, pp. 704-711.

Demarchi, D. A. 2009. "Microsatélites, diversidad y distancias génicas en poblaciones nativas sudamericanas”. Revista Argentina de Antropología Biológica, 11, pp. 73-88.

Demarchi, D. A.; Colantonio, S. E. y Marcellino, A. J. 1998. "Population structure and the uniqueness of the Ayoreo". American Journal of Human Biology, 10, pp. $120-121$.

Demarchi, D. A.; Panzetta-Dutari, G. M.; Motran, C. C.; López de Basualdo, M. A.; Marcellino, A. J. 2001. "Mitochondrial DNA haplogroups in Amerindian populations from the Gran Chaco”. American Journal of Physical Anthropology 115, pp. 199-203.

Demarchi, D.A. y Mitchell, R. J. 2004. "Genetic structure and gene flow in Gran Chaco populations of Argentina: evidence from Y-chromosome markers”. Human Biology, 76, pp. 413-429.

Dornelles, C. L.; Battilana, J.; Fagundes, N. J.; Freitas L. B.; Bonatto, S. L. y Salzano, F. M. 2004. "Mitochondrial DNA and Alu insertions in a genetically peculiar population: the Ayoreo Indians of Bolivia and Paraguay". American Journal of Human Biology 16, pp. 479-488.

Fox, C. L. 1996. "Mitochondrial DNA haplogroups in four tribus from Tierra del FuegoPatagonia: inferences about the peopling of the Americas". Human Biology. 68, pp. 855-871.

García, A. y Demarchi, D. A. 2009. "Incidence and Distribution of Native American mtDNA Haplogroups in Central Argentina”. Human Biology 81, pp. 59-69. 
Harpending, H. C. y Jenkins, T. 1973. "Genetic distance among southern African populations". En: Methods and Theories of Anthropological Genetics, M.H. Crawford and P.L. Workman, eds. Albuquerque, NM: University of New Mexico Press, pp. 177-199.

Harpending, H. C. y Ward, R. H. 1982. "Chemical systematics and human populations". En: Biochemical Aspects of Evolutionary Biology, M. Nitecki, ed. Chicago, IL: University of Chicago Press, pp. 213-256.

Jobling, M. A.; Hurles, M. E. y Tyler-Smith, C. 2004. Human Evolutionary Genetics: Origins, Peoples and Disease. New York, Garland Science.

Kohlrausch, F. B.; Callegari-Jacques, S. M.; Tsuneto, L. T.; Petzl-Erler, M. L.; Hill, K.; Hurtado, A. M.; Salzano, F. M. y Hutz, M. H. 2005. "Geography influences microsatellite polymorphism diversity in Amerindians". American Journal of Physical Anthropology 126, pp. 463-470.

Kruskal, J. B. 1964. "Multidimensional scaling by optimizing goodness of fit to a nonmetric hypothesis". Pyschometrika 29, pp. 1-27.

Mendoza, M. 2003. Range area and seasonal campsites of Toba bands in Western Chaco, Argentina. Before Farming 4, pp. 1-12.

Nei, M.; Tajima, F. y Tateno, Y. 1983. "Accuracy of estimated phylogenetic trees from molecular data. II. Gene frequency data". Journal of Molecular Evolution 19, pp. $153-70$.

Pauro, M.; García, A,; Nores, R. y Demarchi, D. A. 2013. Analysis of uniparental lineages in two villages of Santiago del Estero, Argentina, seat of "Pueblos de Indios” in colonial times. Human Biology 85 (5), pp. 699-719.

Ramallo, V.; Santos, M.; Muzzio, M.; Motti, J.; Salceda, S. y Bailliet, G. 2009. “Linajes masculinos y su diversidad en comunidades Wichí de Formosa". Revista del Museo de Antropología, 2, pp. 67-74.

Reddy, B. M.; Demarchi, D. A. y Malhotra, K. C. 2001. "Patterns of Biological Variation Among the 20 Endogamous Groups of Dhangar Caste-Cluster of Maharashtra, India”. Collegium Antropologicum 25, pp. 425-442.

Relethford, J. 2012. Human Population Genetics. Wiley-Blackwell, New York.

Salzano, F. M.; Pages, F.; Neel, J. V.; Gershowitz, H.; Tanis, R. J.; Moreno, R.; Franco, M. H. L. P. 1978. "Unusual blood genetic characteristics among the Ayoreo Indians of Bolivia and Paraguay". Human Biology, 50, pp. 121-136.

Santos, F. R.; Pandya, A. y Tyler-Smith, C. 1999. The Central Siberian Origin for Native American Y Chromosomes. Am. J. Hum. Genet. 64, pp. 619-628.

Schmitt, R.; Bonatto, S. L.; Freitas, L. B.; Muschner, V. C.; Hill, K.; Hurtado, A. M. y Salzano, F. M. 2004. "Extremely limited mitochondrial DNA variability among the Aché Natives of Paraguay". Annals of Human Biology 31, pp. 87-94.

Takezaki, N. y Nei, M. 1996. "Genetic distances and reconstruction of phylogenetic trees from microsatellite DNA". Genetics 144, pp. 389-399.

Takezaki, N. y Nei, M. 2008. "Empirical tests of the reliability of phylogenetic trees constructed with microsatellite DNA". Genetics 178, pp. 385-392. 
Tomasini, A. y Braunstein, J. 2006. "Geografía y sociedades tradicionales del Gran Chaco”. Folia Histórica del Nordeste, 16, pp. 173-185.

Underhill, P. A.; Jin, L.; Zemand, R.; Oefner, P. J.; Cavalli-Sforza, L. 1996. A precolumbian $\mathrm{Y}$ chromosome specific transition and its implications for human evolutionary history. National Academy of Science 93, pp. 196-200.

Wright, S. 1951. "The genetical structure of populations". Annals of Eugenics 15, pp. 323354. 